Martin McLaughlin, Javier Muñoz-Basols (eds.) (2021)

\title{
Ideology, Censorship and Translation
}

\section{London and New York: Routledge; pp. 133}

La obra Ideology, Censorship and Translation (Ideología, censura y traducción) editada por Martin McLaughlin y Javier Muñoz-Basols, profesores e investigadores de la Universidad de Oxford (Reino Unido), publicada en inglés en la prestigiosa editorial Routledge, es un volumen compuesto de ocho capítulos escritos por diferentes autores y una introducción de los editores. Los capítulos están organizados cronológicamente y analizan diferentes temas y géneros (textos científicos, industria editorial, propaganda, traducciones de obras literarias, teatro, cine, estudios culturales, ensayos filosóficos y críticos, historia de las ideas, teoría de la traducción y relaciones de poder). La temática del volumen versa sobre cuestiones siempre actuales referentes a la ideología y la censura e invita al lector a reflexionar sobre el papel de la traducción a lo largo de la historia y en la actualidad como también sobre las repercusiones éticas y el involucramiento ideológico del traductor en diferentes épocas y contextos. Este volumen especial es un libro importante no solo para los expertos en el tema, los teóricos de la traducción y los traductores, sino también para el público general que de esta manera obtiene un conocimiento sobre la importancia y las repercusiones en la sociedad de la traducción tanto en su aspecto práctico como en el teórico y de su papel crucial en la vida del ser humano y de la sociedad global en general.

El primer capítulo «Notes of Charles Darwin's thoughts on translation and the publishing history of the European versions of [On] the Origin of Species» escrito por Carmen Acuña-Partal, de la Universidad de Málaga (España), versa sobre un tema poco tratado en el marco de la traducción, es decir, las implicaciones ideológicas en la traducción de textos científicos. La autora presenta la historia de las traducciones de la obra de Darwin y los esfuerzos y el involucramiento del autor en el proceso de traducción para encontrar traductores competentes. Sin embargo, Darwin no pudo evitar las manipulaciones ideológicas debidas a la censura, las estrategias comerciales de las casas editoriales, la ideología política, la resistencia del ámbito científico tradicional y la influencia de la iglesia, ya que su obra significó una revolución científica e intelectual minando los fundamentos tradicionales de la religión y la moral a escala mundial. Su libro sufrió innumerables manipulaciones, transformaciones, adaptaciones de las traducciones en diferentes lenguas y en diferentes 
países del mundo. La autora presenta un recorrido por las traducciones en Europa. Así, por ejemplo en España, las traducciones publicadas en las primeras décadas del siglo XX, antes de la Guerra Civil, fueron prohibidas durante la primera época del franquismo.

Marcos Rodríguez-Espinosa (Universidad de Málaga, España), en su ensayo « ¡No pasarán!': Translators under siege and ideological control in the Spanish Civil War» rastrea las biografías de un grupo de traductoras e intérpretes que trabajaron durante la Guerra Civil para la parte republicana. Las potencias de Occidente proclamaron su neutralidad ante el conflicto civil que se desenvolvía en España. No obstante, la Unión Soviética, que también había proclamado su neutralidad, frente al apoyo cada vez mayor de los regímenes nazi y fascista a la parte franquista, cambió de estrategia y comenzó a apoyar a las fuerzas republicanas. Para ello necesitó un número significativo de intérpretes y traductores cuyos servicios fueron cruciales en la colaboración del régimen soviético y el gobierno republicano. La mayoría eran mujeres licenciadas en las universidades soviéticas. Después de recibir un entrenamiento en Moscú, fueron enviadas como traductoras militares a España. Es, por ejemplo, el caso de la legendaria Maria Alexandrova Fortus que combinaba el trabajo de traductora e intérprete con el de agente secreto, o el de las hermanas Paulina y Adelina Abramson. Como faltaban lingüistas calificados en el marco militar, comenzaron a contratar traductoras civiles. El autor menciona, entre otras, a Lydia Kúper y a Irene Falcón, asistente de Dolores Ibárruri. Las traductoras e intérpretes trabajaban en lugares y situaciones peligrosos, en un campo de batalla extremadamente polarizado y frecuentemente se las consideraba sospechosas o se las acusaba de espionaje y/o traición. Al terminar la Guerra Civil, la mayoría de las traductoras tuvieron que exiliarse a causa de la derrota de la República y algunas por oponerse a la ortodoxia soviética. El autor destaca también la importancia de las memorias y autobiografías escritas por las traductoras de la Guerra Civil Española que en sus crónicas presentan cómo fue su trabajo en época de guerra y revelan aspectos de la historia del conflicto.

En «The censorship of theatre translations under Franco: the 1960s» Raquel Merino-Álvarez, de la Universidad del País Vasco, Vitoria-Gasteiz (España), analiza las traducciones de las obras de teatro extranjeras en la España franquista de la década de los 6o. El Archivo General de la Administración es la única fuente de información acerca de las obras de teatro y las traducciones de obras extranjeras en la época franquista. La autora presenta el caso polémico de la traducción y representación de ¿Quién teme a Virginia Wolf? de Edward 
Albee. Esta obra fue estrenada en febrero de 1966 en el Teatro Goya de Madrid después de un complejo proceso de censura. El ensayo analiza el papel de los traductores profesionales en el marco de la censura del teatro español. En el mundo del teatro la traducción es casi siempre un proceso invisible y la mayoría de los traductores que trasladaron las obras del original a la lengua meta permanecieron desconocidos. La autora destaca la trayectoria profesional del traductor de teatro Méndez Herrera y se centra en su traducción de la mencionada obra de Albee. Su representación en el Teatro Goya es una clara señal de cambio, de relajamiento de la censura y un cierto grado de apertura.

El cuarto ensayo, escrito por Emily Ligo, de la Universidad de Exeter (Reino Unido), «Between ideology and literature: Translation in the USSR during the Brezhnev period» analiza la labor traductora después de la época de deshielo de Jrushchov, cuando llega al poder Brézhnev y con él la vuelta hacia un cierto neo-estalinismo en la Unión Soviética. Sin embargo, como lo demuestra la autora, no se produjo un cierre total en cuanto a la traducción de obras literarias extranjeras, como tampoco en otras áreas de la actividad cultural. Los editores y los traductores tenían que buscar el equilibrio entre ideología y censura, y las consideraciones pragmáticas cómo satisfacer la demanda de los lectores soviéticos de literatura occidental. El análisis de las traducciones literarias publicadas entre 1965 y 1981 en la revista Novyi mir, que publicaba regularmente traducciones de autores occidentales, especialmente en la época de Jrushchov, y tenía un gran renombre entre los intelectuales, demuestra que la publicación de literatura extranjera traducida al ruso no sufrió un estancamiento directo y obvio en la revista. La autora llega a la conclusión sorprendente de que disminuyó la publicación de traducciones de obras de autores soviéticos que no escriben en ruso, lo que se debe probablemente a la creciente "rusificación" de la sociedad.

Pilar Godayol, de la Universitat de Vic-Universitat Central de Catalunya (España), es autora del quinto capítulo «Censorship and the Catalan translations of Jean-Paul Sartre» dedicado al análisis del proceso de censura de ocho obras traducidas de Sartre, siete de las cuales obtuvieron el permiso de publicación y salieron a la luz entre 1965 y 1973 en Barcelona. La metodología adoptada para este estudio se basa en el concepto de microhistoria de Jeremy Munday (2014). La autora estudia el microcontexto histórico del proceso de censura, desde la solicitud para la publicación de las traducciones catalanas de ocho obras de Sartre hasta el permiso final para siete de ellas. Partiendo del análisis de ocho informes de censores consultados en el Archivo General de la Administración, 
Godoy llega a conocer cómo reaccionaba el régimen de Franco frente a la posibilidad de publicar las traducciones catalanas de Sartre, quiénes fueron los censores, cómo argumentaban sus decisiones, cómo se desarrollaba el proceso de censura para cada una de las obras de Jean Paul Sartre. Finalmente, responde a las preguntas sobre por qué permitieron la publicación a pesar de que Sartre era un escritor prohibido por la Iglesia Católica, y por qué las primeras obras de Sartre autorizadas por el Ministerio de Información y Turismo durante el régimen dictatorial de Franco fueron justamente las traducidas al catalán.

Jeroen Vandaele de la Universidad de Gante (Bélgica) es el autor del sexto ensayo titulado «What is an author, indeed: Michel Foucault in translation». El autor introduce algunos conceptos básicos de la traductología y analiza las obras de Paul-Michel Foucault. Se dirige tanto al lector general como a los especialistas de Foucault y se centra en el problema de la traducción considerando que las traducciones de Foucault son un área que merece más atención que unas simples notas sobre la traducción o solicitudes para la re-traducción. Comparando las traducciones de un capítulo de Surveiller et punir (1975) ('Les moyens $d u$ bon dressement') en inglés, español y noruego, demuestra que estas traducciones no son de ninguna manera «el mismo texto en otra lengua». Los conceptos más importantes de Surveiller et punir se expresan con una limitada serie de palabras (pouvoir, discipline, surveillance) que se repiten a lo largo del texto transformándose en el discurso de Foucault en potentes conceptos que deberían reflejarse en las traducciones.

«Censoring Lolita's sense of humor: When translation affects the audience's perception», un ensayo de Patrick Zabalbeascoa de la Universitat Pompeu Fabra de Barcelona (España), analiza las versiones cinematográficas realizadas por Stanley Kubrick (1962) y Adrian Lyne (1997) de la novela de Vladimir Nabokov Lolita (1955). El autor compara la novela con las dos versiones cinematográficas y se concentra en el humor y las sutilezas de la censura teniendo en cuenta que las dos adaptaciones cinematográficas aparecieron en diferentes épocas y contextos histórico-sociales. A través de un análisis micro-textual detallado el artículo presenta interesantes facetas de la naturaleza del humor considerando que la traducción audiovisual debe tener en cuenta toda una serie de diferentes componentes textuales y extra-textuales, verbales y no verbales, como palabras, elementos paralingüísticos, música, fotografía, narrativa cinematográfica, movimientos de la cámara, tomas, ángulos. El análisis de las traducciones en alemán y español de la versión de Kubrick ilustra toda una 
serie de problemas de traducción y demuestra la importancia de traducir el humor ya que los errores y deficiencias deliberadas o no podrían constituir una forma de censura sin la presencia de un censor activo teniendo como resultado una calidad inferior y pérdida de interés.

El último capítulo de esta edición especial, «The crooked timber of self-reflexivity: Translation and ideology in the end times», de Stefan Baumgarten, de la Universidad de Graz (Austria), cuestiona el papel del traductor y de la traductología del siglo XXI. Analiza diferentes fenómenos de traducción desde distintas perspectivas, teóricas, auto-reflexivas, ético-ideológicas. Si la ideología es omnipresente, también lo debe ser la auto-reflexión, opina el autor. Baumgarten explica que vivimos en una sociedad en la que las estructuras de la dominación y la supremacía siguen dictando las relaciones de poder que penetran en el discurso académico: estamos atrapados en un orden mundial (pos)neoliberal en el que los valores capitalistas están cada vez más arraigados volviéndose una norma incuestionable. Considera que deberíamos comenzar a percibir el fenómeno de la traducción con auto-reflexión y desde una perspectiva ético-ideológica. Existen investigaciones prometedoras, también en el campo de la traductología, que cuestionan la hegemonía cultural del sistema de valores anglófono y sus epistemologías subyacentes dejando al descubierto las raíces intelectuales de la amenaza epistémica que presenta el discurso anglófono a las formas alternativas del conocimiento. Propone introducir en el discurso de la teoría traductológica el concepto de 'begemonic non -translation' (la traducción no hegemónica). El último ensayo de este volumen especial nos incita a pensar sobre la situación actual de la traducción tanto desde el punto de vista teórico como desde la perspectiva aplicada y nos enfrenta a ideas desafiantes sobre su futuro.

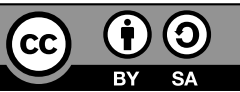

Jasmina Markič

Universidad de Ljubljana 